\title{
Collaborative business model development for home energy renovations
}

\author{
E. Mlecnik • A. Straub • T. Haavik
}

Received: 20 October 2017 / Accepted: 8 April 2018/Published online: 28 April 2018

(C) The Author(s) 2018

\begin{abstract}
In the EU, housing retrofit rates have to increase to about $2.5-3 \%$ of the housing stock per year to achieve policy goals. The development of new business models and collaboration of SMEs in a fragmented market is expected to result in an increase in home renovations. This study presents a way to better understand the usefulness of the business model as a market device for collaborating firms for realising home energy renovations, by analysing literature and action research observations. Joint innovation decisions during business model development were traced back for 24 groups emerging from the supply side in five European countries. Commonalities for all groups were analysed to understand the usefulness of the business model. The business model development experiences show that effort is still required to support SME collaboration and to
\end{abstract}

\section{E. Mlecnik $(\bowtie)$}

Faculty of Architecture and the Built Environment, Management in the Built Environment, Delft University of Technology,

P.O. Box 5043, NL-2600 GA Delft, Netherlands

e-mail: e.mlecnik@tudelft.nl

\section{A. Straub}

Faculty of Architecture and the Built Environment, OTB Research for the Built Environment, Delft University of Technology,

P.O. Box 5043, NL-2600 GA Delft, Netherlands

e-mail: a.straub@tudelft.nl

T. Haavik

Segel A.S., Øyane 11, P.O. Box 284, N-6771 Nordfjordeid, Norway

e-mail: trond@segel.no introduce basic marketing knowledge within SMEs, particularly to identify the customer segment and its values and to clarify the effectiveness of existing communication channels. Business models appear to be very useful for collaborative vision formation and networking and for clarifying the need of customer-oriented approaches that include project management and structured guidance of homeowners. However, they do not readily lead to the introduction of collaborative businesses, for which action plan are needed. Collaborating companies are advised to pay specific attention to identifying quality assurance and independent advice for home energy renovations. The research acknowledges the success of action-based research approaches to support collaborative business development and recommends its future use to speed up market development.

Keywords Innovation · Housing C Collaboration · Energy renovation $\cdot$ Energy efficiency $\cdot$ Business models

\section{Introduction}

Renovation of buildings is key to meet the EU's energy efficiency targets (Artola et al. 2016). The European Union identified the need to reduce carbon emissions in residential sectors by $88-91 \%$ in 2050 compared to emission levels in 1990, in order to transform the current economy into a competitive low-carbon one (EU 2011). The residential sector, representing $17 \%$ of global $\mathrm{CO}_{2}$ 
emissions, has a considerable role in mitigating global climate change (Nejat et al. 2015). To reduce carbon emissions, the widespread introduction of energy efficiency is one of the most important drivers. European buildings account for approximately $40 \%$ of energy use. European residential buildings are estimated to represent $27 \%$ of the total energy-saving potential by 2020 (Tuominen et al. 2012).

Efficiency retrofits present a tremendous opportunity to decrease energy use worldwide (Güneralp et al. 2017). Approximately $45-60 \%$ of the total number of dwellings in many of the EU Member States was built during the post-war period (between 1946 and 1980) when there were no energy efficiency requirements for buildings (Eurostat 2011). Of the dwellings in the EUexcluding Croatia and Finland-64.3\% are owneroccupied (Eurostat 2011). Some countries with very high levels of owner-occupied housing, for example Belgium, have a large number of pre-war buildings (Hilderson et al. 2010). However, depending on the EU Member State, only $0.4-1.2 \%$ of the stock is renovated each year (EC 2016). It is unlikely that this $1.2 \%$ is renovated to the required high standards of energy efficiency (BPIE 2011; Tofield and Ingham 2012). In the $\mathrm{EU}$, retrofit rates also have to increase to around 2.5-3\% of the housing stock per year to achieve policy goals (Sandberg et al. 2016).

The delivery of energy renovations in the EU is hindered by financial, technical, process, regulatory and awareness barriers (Haavik et al. 2012c; Artola et al. 2016). Most literature describes how regulatory, financial and fiscal policies and information campaigns and labelling can help eliminate these barriers (Artola et al. 2016). The need for developing skills and capacities in the existing supply side is much less addressed. Rødsjø et al. (2010) discussed the need for a market development perspective in innovation phases, and highlighted the importance companies should attach to innovation learning, finding complementary partners and communicating customer needs, when introducing advanced home renovation business. For the home renovation sector, authors now confirm the attractiveness and importance of new business models (Aho 2013; Artola et al. 2016; Abuzeinab et al. 2018) and the need for complementary partners for collaboration (Mlecnik 2013). Now, an innovation prospect is to embed collaborative business model development into the home renovation sector.

\section{Research goal}

This research aims to better understand the usefulness of the business model as a market device for collaborating firms (further called 'consortia') for realising owneroccupied energy renovations, by analysing literature and specific experiences from a European project (COHERENO 2016). The overall objective of this Intelligent Energy Europe funded project (2012-2016) was to strengthen collaboration of enterprises in innovative business schemes for the realisation of owneroccupied single-family home (SFH) energy renovations. In this research, we specifically focussed on learning from the experiences of companies who are jointly developing a business, to better understand concerns regarding collaboration and to observe if the business model can improve market understanding for SFH energy renovation.

\section{Research method}

To better understand the usefulness of collaborative business model development, we used two complementary methods: literature review and observations from action research (see for example, Reason and Bradbury 2005). Action research is a social research carried out by a team that encompasses a professional action researcher and the members of an organisation, community or network ('stakeholders') who are seeking to improve the participants' situation (Greenwood and Levin 2007). Regarding the urgency of market development of home energy renovations, such a research approach is most relevant.

We first examine existing literature regarding home renovation from a supply-side perspective, focussing on the collaboration issues for achieving deep renovations of owner-occupied homes. We then discuss the position of the business model as a market device to support collaboration in the supply side.

The action research was identified by the authors for change agents in five countries (Austria; Belgium; Netherlands; Norway; Germany). These change agents all used the same approach we identified for strengthening collaboration of enterprises in innovative business schemes for the realisation of owner-occupied SFH energy renovations. All change agents first attracted supply-side actors who wanted to collaborate in integrated SFH renovation schemes in an open 'business 
collaboration event'-supported by a matchmaking website - where the change agents introduced business model development opportunities and highlighted their possible (free-of-charge) support for joint business development. After this networking, interested supply-side actors identified local groups to jointly develop a business model, facilitated by the local change agents. The change agents then facilitated the same business development method in all countries, which was identified based on existing guidelines (One Stop Shop 2012) to guarantee the impartiality of the approach and the same data collection for participatory action research observation.

First, all emerging groups provided outcomes in the same format of a PEST analysis (Political, Economic, Social and Technological factors) and identified influencing factors in the same format of a 'competitive arena', using the 6-Forces model, which addresses issues related to suppliers, competitors, potential competitors, substitutes, complementary businesses and customers. Results from these analyses for the individual consortia were compiled and categorised into an overall SWOT analysis to identify common strengths, weaknesses, opportunities and threats. The Osterwalder and Pigneur (2010) 'business model canvas' was then introduced by the local change agent as a market/action research device to support each consortium. Based on the outcome of this exercise, each consortium formulated a specific action plan outlining a timeframe, responsibilities and the necessary financial and human resources.

In this research, we thus regarded 'collaboration for integrated SFH renovation' as a process innovation, as this idea was new to the supply-side actors involved. Innovation can be defined in many ways, see for example, Rogers (2003). In this work, we chose to define 'innovation' as expressed by West et al. (2004) for organisational and management innovation: 'the intentional introduction and application within a job, work team or organization of ideas, processes, products or procedures which are new to that job, work team or organization and which are designed to benefit the job, the work team or the organization'. The action research contribution - which tried to understand the adoption of this innovation - is illustrated in Fig. 1, following the logic of innovation adoption decision processes as identified by Rogers (2003).

The authors instructed all change agents on how to facilitate all business model development processes.
Our action research observations continuously mapped the barriers the consortia faced, and their views on the market prospects and collaborative context. The participating business developers used the business model as a marketing device, while our task was to understand how the business model stimulates innovation decisions and joint market development. Furthermore, a year after the groups launched their business model, the researchers interviewed the main business model owners and reviewed marketing documents to learn from the outcomes of the business development into action. This provided insights if the jointly developed business models were adopted or rejected.

The individual business models owned by the consortia should be regarded in their country-specific context and will not be discussed in detail in this paper. Because the composition of the groups varied for each group, we will also not address the role and importance of specific stakeholders, such as contractors, architects, installers, networks and other professionals and intermediaries. Instead, this paper discusses the commonalities found from the joint business development process, as this process was similar for 24 business consortia.

We now first discuss the main literature findings to better understand the usefulness of the business model as a market device for collaborating SMEs for realising home energy renovations, and then introduce the action research findings regarding SFH energy renovations.

\section{Literature review}

The home construction sector is dominated by SMEs who have limited competencies and resources for innovation (Mlecnik 2013). Amongst others, the innovation risks related to introducing sustainability approaches and the fear of high transaction costs associated with building up new knowledge are hindering engagement of SMEs. Small builders can be innovative if clients allow time and money for experimentation (Killip 2013), but to bridge the gap to early adoption, other ways have to be found. Large enterprises might have more innovation opportunity but often show cumbersome organisational models (Disconzi and Lorenzoni 2017). Also, the project-based nature of the construction industry makes the emergence of systemic innovation for achieving high energy efficiency and collaborations beyond ad hoc less likely (Mlecnik 2013). 


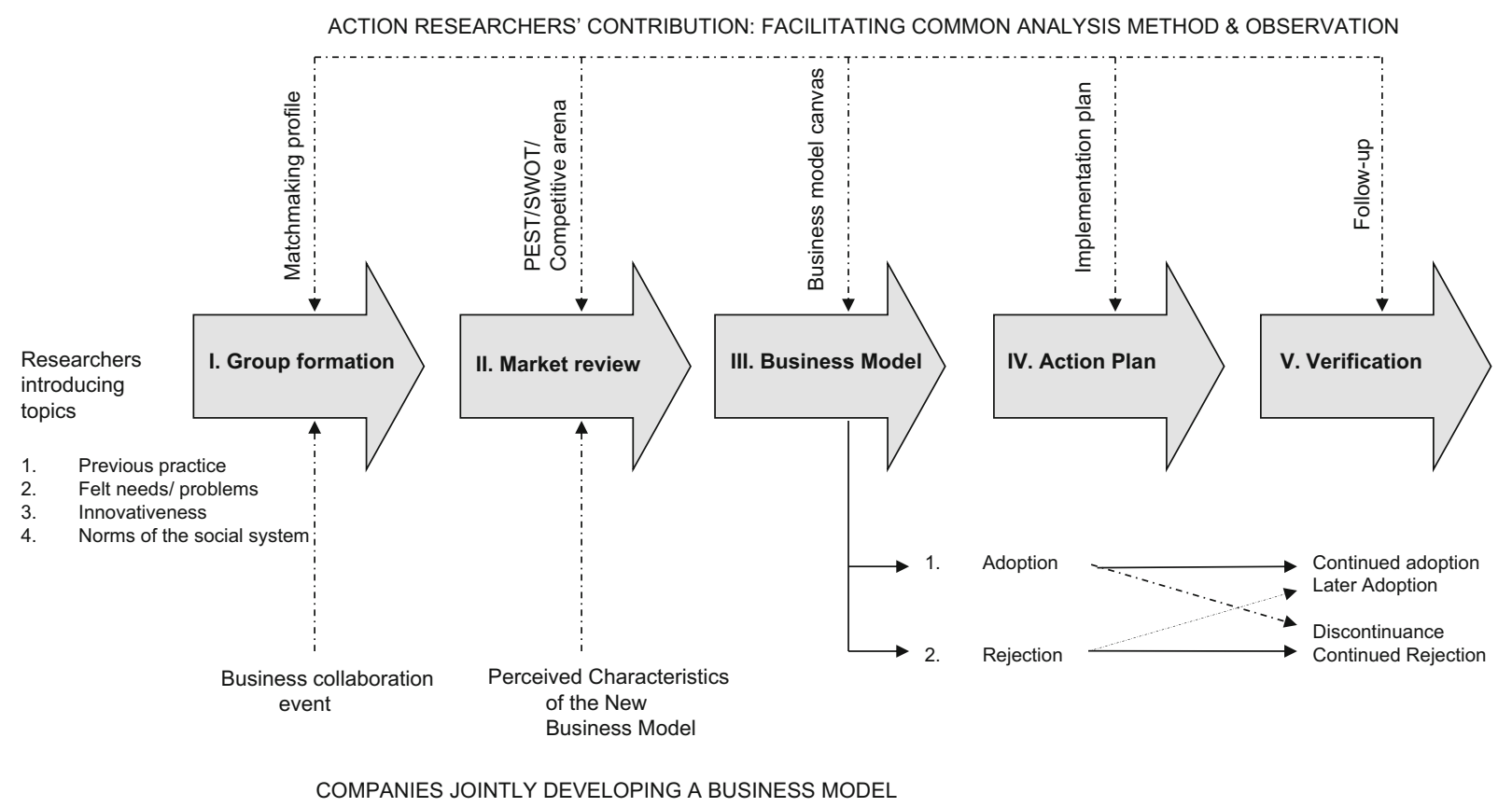

Fig. 1 Action research process related to the adoption of business models

If the goal is to speed up market development of energy renovations, conventional roles, trades and professions can be questioned as integrated services are not always achieved (Killip et al. 2014). In practice, a shift away from standard relationships can appear, such as experienced in multi-skilled risk-sharing teams and cooperative models for organising work (Killip et al. 2014). The fragmentation of the supply-side also backfires at the decision-making to renovate, as the homeowner regards the management of different professionals as an important burden (One Stop Shop 2012; SuccessFamilies 2012; COHERENO 2016). In owneroccupied homes, homeowner decisions to renovate with efficiency measures are the necessary precursor to energy-saving outcomes (Wilson et al. 2018).

Particularly, the home renovation market is still largely dominated by micro-enterprises offering single products or services, some of which are even beyond the reach of current policy (Owen et al. 2014). This can bring knowledge gaps, uncertainty on who is responsible and poor communication, ultimately resulting in a design-performance gap (Killip et al. 2014). Risholt and Berker (2013) discuss the importance of craftsmen aiming for good project management, but other authors also emphasise a possible important role by public actors and research institutes (Rødsjø et al. 2010), the middle field (Kivimaa and Martiskainen 2017) or networks (Ornetzeder and Rohracher 2009).

Particularly, collaboration for lean and agile construction processes is known to be hindered by the lack of - or informal nature of - tacit knowledge sharing, which can lead to breakdown in trust and inefficient process integration (Saini et al. 2018). Overall, networks of collaborating stakeholders are known to be an important factor in the introduction, implementation and sharing of new technological solutions (Porter 1998). Benefits generated by collaborative networks impact the entire lifespan of an enterprise, and empirical studies have confirmed that collaborating firms are more innovative than non-collaborating ones (OECD 2001). Operational activities of multiplayer networks should focus on reinforcing conditions and communicative activities that support innovation-decision processes from one step to the next (Mlecnik 2016).

Adoption of energy efficiency innovation by suppliers can also be hindered by lack of local market, thus introducing a need for SMEs to jointly formulate a vision, learning and network (Mlecnik 2014). Also, policy makers observe a need to increase market size for the uptake of structured business solutions for home energy renovations. For example, local and regional authorities have started combining support, guidance and group purchasing of energy renovation services that 
work as a possible method of accelerating the retrofitting of the existing housing stock (Ruelle and Teller 2016), thus creating an opportunity for collaborating SMEs to develop specific offers for larger groups of homeowners. In some regions, even specific innovation subsidies were introduced to stimulate better customer-orientation and collaboration of SMEs for specific home renovation markets (KP Renovatie 2017). Such developments can spur companies' interest to jointly identify a new or adapted business model.

New collaborative business developments include for example the introduction of a step-by-step offer, presenting multiple measures in a predefined timeframe or the development of a more structured and holistic offer, supporting the homeowners in the decisionmaking process (Galiotto et al. 2016). Vanhoutteghem et al. (2011) describe such a full-service renovation concept that includes all aspects of the renovation process, i.e. initial evaluation, thorough analysis, proposal of an integrated set of solutions and execution coordinated by a dedicated project manager, as well as a focus on quality assurance and continued commissioning of the house. This idea was further picked up only a few collaborating SMEs in projects such as 'SuccessFamilies' (2012), 'One-Stop-Shop' ( 2012), 'Refurb' (2017), and 'BetterHome' (2017). The idea behind a so-called one-stop-shop service is to focus on assisting the homeowner by looking at many different aspects of renovation, and not only energy, to encourage the homeowner to choose the optimal renovation for his/ her specific house (Grøn Bjørneboe et al. 2017).

These observations from literature confirm that the home renovation market is still highly fragmented, and better collaboration of supply-side actors is often put forward as an initial step towards progress. Some experiences show that it might be beneficial to team up with local authorities, participation experts, project managers, etc. to engage in neighbourhood actions or group offers. The engagement of intermediaries - which can include both public and private stakeholders - can also be important for facilitating individual building projects, creating niche markets, implementing new practices, supporting the creation of new business models and facilitating building use post-construction (Kivimaa and Martiskainen 2017). Various researchers (Haavik et al. 2012a, 2012b, 2012c; Mlecnik et al. 2012; Mahapatra et al. 2013; Mlecnik et al. 2013) suggest that supply-side activation should aim for innovative and cooperative business models, where various professionals collaborate to reduce fragmentation and to lessen the burden on the homeowner.

Business models can serve as pivotal catalysts for the spread of innovations by examining the logic behind economic value creation and increased marketability and sustainability (Osterwalder 2004; Teece 2010). The development of business model research in the building and construction disciplines is still in an emerging stage (Abuzeinab et al. 2018). Using a business model as an intermediary market device between different innovation actors (Doganova and Eyquem-Renault 2009) can provide new insights, for example, on how consortia should address customer values and activities. The business model can connect actors aspiring sustainable innovations through narratives and calculations (Boons and Lüdeke-Freund 2013).

Only a few researchers have adopted business model research for analysing energy renovations in singlefamily homes, such as Haavik et al. (2012a, 2012b, 2012c), Mahapatra et al. (2013), Mlecnik and Straub (2014, 2015) and Grøn Bjørneboe et al. (2017). Developing and testing new business models for implementing energy renovations can include offering full-service packages, including first contact, energy consulting, financial packages, renovation works and commissioning, expressed in the previously described one-stop-shop developments. Key customer values in such business models are, for example, less of a burden on the client and offer quality assurance or energy performance agreements (One Stop Shop 2012; SuccessFamilies 2012, Mlecnik et al. 2013, Mahapatra et al. 2013; van Holm et al. 2016).

Various authors suggested that a better understanding of the business case regarding value creation and exploration of new working methods-such as business model development - can address particular learning and speed up market development (Pitt et al. 2009; Häkkinen and Belloni 2011; Mahapatra et al. 2013; Aho 2013; Al-Saleh and Mahroum 2015; Abuzeinab et al. 2018). Particularly, Sommer (2012) suggested the need for qualitative methods to better understand the management framework for business models. Our action research was therefore designed to support innovation for SMEs, by developing and testing a collaborative business model development method to improve SME's marketing skills and collaboration opportunities. We chose to focus specifically on the renovation of owner-occupied singlefamily homes. 


\section{Action research results}

The COHERENO project started from an open mindset, and it was only identified by the partners that supply-side actors would be their primary target group to address innovation for SFH energy renovation. The project invited all types of regional supply-side actors to find each other without a predefined structure. This was for example done by designing the same type of business collaboration event in each country and by providing an internet-based business profiling platform. Collaborating companies thus found each other, facilitated by the project. Overall, the project partners offered change agents that enabled and mediated the consortium formation, but the aggregation and consolidation was done by the businesses themselves.

The business collaboration events resulted in 24 emerging consortia in Austria (5), Belgium (5), Netherlands (5), Norway (5) and Germany (4). The final composition of the 24 consortia that went on with the business development is illustrated in Fig. 2. Figure 2 shows that a variety of stakeholders were willing (and able) to work together to develop a business model for SFH energy renovations. Most of the business models were initiated by private renovation professionals (mostly consultants, e.g. architects, energy advisors and/or contractors) who took the lead in forming a consortium. In some cases, a public intermediary (e.g. a local authority and/or a non-profit organisation) took the initiative and developed the business model. The different contributing consortium members took on specific roles in the homeowner's customer journey, from informing and consulting to contracting, executing and assuring quality. The size of the consortia varies according to the business model and collaboration needs (Fig. 2).

Differences in composition could only partially be related to differences on location (i.e. differences according to the country in which the model exists). For example, in Belgium, the involvement of specific consultants is always necessary because of the protected position of the architect: every major renovation has to be filed by an architect, and every energy performance certificate has to be filed by an accredited trained energy expert. In contrast, Norwegian consultants are not as involved in retrofitting projects, which explains why all Norwegian consortium models are dominated by contractors. In the other studied countries, a more mixed picture is observed. Germany and Belgium developed some working business models where public intermediaries took the initiative to promote more $\mathrm{SFH}$ energy renovations with a specific business model.

As these consortia showed many differences in composition, it is less pertinent to discuss the role of different types of stakeholders in the process. However, there were many commonalities on how the groups perceived needs and influences for their business development process.

The observations during the formation process confirm that all consortia emphasised the need for motivated team members and at least one member with experience in the SFH energy renovation market, to be able to show expertise to the homeowner. Some consortia identified the need for additional knowledge before entering the market of SFH renovation, which was then provided by other consortium members. For example, some consortia had difficulties interpreting the size of the local market and the need to address specific building typologies or costumer segments. A knowledge exchange between project members led to build up of trust amongst consortium members.

Main joint findings from the further steps in the business model development (identification of PEST/ SWOT analysis and competitive arena) identified the need in all groups to specify an offer that is competitive with traditional suppliers and installers providing single renovation measures. All groups wanted to develop an offer that is authentic and that goes beyond technological and financial solutions, also addressing emotional, sustainable and historic values. Another commonality for all groups was their wish to streamline first contact, advice, sales and after sales and confirmed the possible benefits of a one-stop-shop approach to quickly respond to customer requests. Although the first idea was retained in all groups, the latter was not always pursued. A few consortia reasoned that an integrated offer might be too expensive. Table 1 further summarises the opportunities and threats for business development perceived at this stage of the business development process, limited to those factors that were common for all consortia.

The introduction of the business model canvas during the process raised the questions who will 'own' the future business and who will be responsible as first contact for the client. Usually, one consortium member stepped forward as business model owner, although in some cases, consortia members identified a new joint company next to their existing activities. In case one consortium member was declared a business model owner, he was not necessarily regarded by the other 


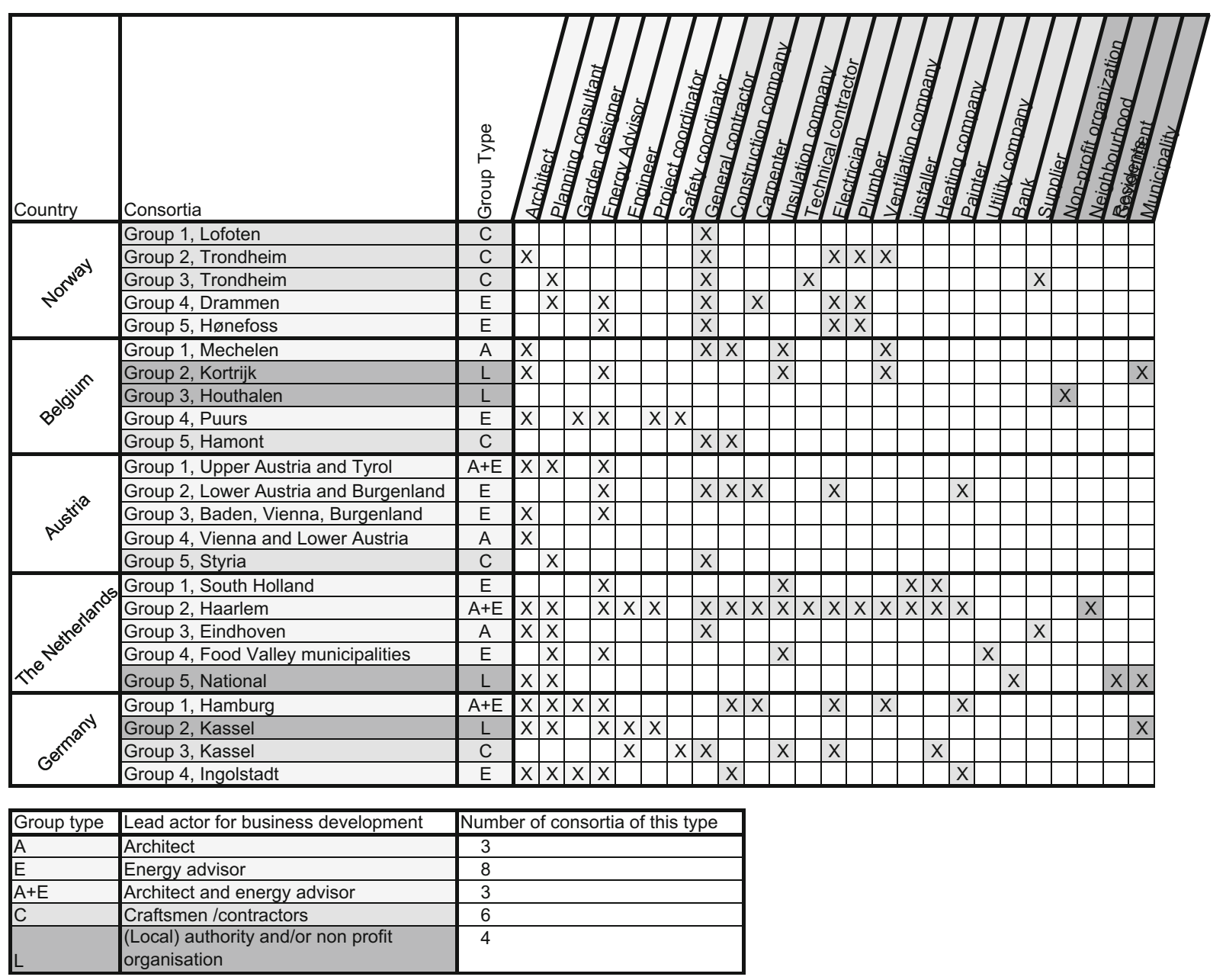

Fig. 2 Composition of consortia offering single-family home energy renovations. Source: COHERENO (2016)

consortium members as an opinion leader, but merely as a change agent. Predefined quality assurance issues were addressed by all consortia as a possible input for the business model to gain customer confidence. However, quality or energy performance guarantees were often abandoned in a later stage in the business model exercise, also because such guarantees are not sufficiently developed in the local market. All groups strived for quality but also had specific concerns related to the cost and availability of (better performing) materials. For some groups, it was particularly cumbersome to identify which member will pay for or organise homeowner advice and project management, and in some cases, a physical renovation shopping point or office.

During the action planning phase, a few consortia reported a current lack of experience in consortium management (e.g. for strategy follow-up, concept marketing of an integrated concept, etc.) or in one case, a wrong choice of a team member. For these groups, reputation and joint competencies still have to be developed. Consortia that were only composed of SMEs frequently reported a perceived need for incremental innovation of the existing products and services and for internal training. The identified solutions for these barriers were usually first home renovation demonstration cases to address project-based learning.

\section{Discussion}

We now discuss how the business model (Osterwalder et al. 2005) itself-particularly the business model 
Table 1 Common opportunities and threats perceived by 24 consortia during their business development for SFH energy renovations

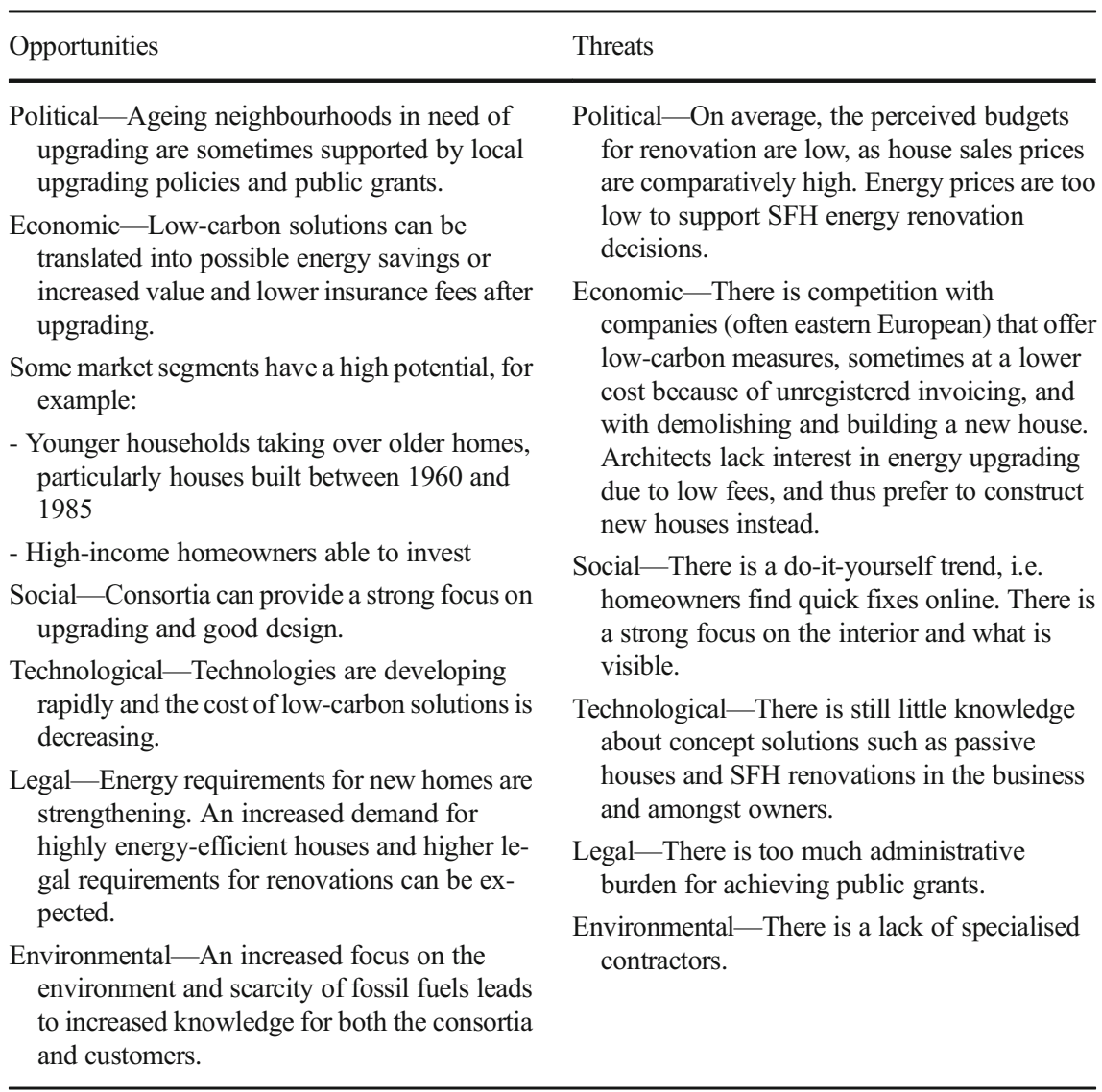

canvas (Osterwalder and Pigneur 2010) tool-was interpreted as a market device for the collaborating firms. We therefore use Sommer's (2012) research analysis development of five essential elements that identify green business models: target group and value proposition - always to be seen in conjunction (Johnson et al. 2008) - key activities, key resources and financial logic - the latter three to be regarded as the response to realise the value proposition. Here, we present these commonalities related to common innovation characteristics as exemplified by Rogers (2003), focussing on observing how the consortium members perceive the relative advantage for themselves and the homeowners, the complexity of collaboration, the trialability in their region, the compatibility with their own businesses and the market visibility.

Target group and value proposition

The companies deliberately had to identify and choose relevant groups to which a value proposition is intended to appeal (Osterwalder and Pigneur 2010). However, initially they struggled to pinpoint the specific needs of the SFH renovation customer. This research finding suggests that SMEs in the construction sector are generally not used to target group-oriented thinking. Almost all consortia define the customer segment in general terms such as 'homeowners with an above average income'. This is based on their market understanding that an SFH energy renovation requires a high upfront investment, which lower-income groups often cannot afford and which the consortium cannot easily facilitate. A majority of the consortia also chose customer segments such as 'young families moving to a larger home', based on their own experiences of their business as usual. Only a few consortia specifically targeted other specific segments such as older homeowners, usually identified as 'empty-nesters'. Although the business model allowed them to reflect about other promising segments, they mostly went for the safest bet that supports incremental innovation.

Approximately half of the consortia identified customer segments as 'types of houses' according to age, 
geography, location within a $50-\mathrm{km}$ radius from the companies, technical characteristics and so on. The reasoning behind this choice is that this can allow prediction of energy savings. However, such a choice does not reflect the persona-based approach that business models represent: it is vital to recognise the values, needs, preferences and behavioural choices of the specific target group (Zenker 2009). Also, this selection method does not take into consideration that homeowners already might have renovated parts of the home which are difficult to detect from statistical data. Only a few consortia also did a detailed analysis to understand if selected houses from a certain construction period or in a specific neighbourhood form an interesting volume market.

All consortia understood that, compared to selling single low-carbon technologies, there has to be a specific reason for initiating the concept of an integrated $\mathrm{SFH}$ renovation, for example, the house needing a facelift or a change in life situation with a need for more space or better accessibility. This was usually correctly reflected on the chosen customer segment. All consortia targeted the 'soft needs' of renovation, such as providing better indoor comfort, environmental contributions, increased home safety and financial security for old age.

All consortia defined good project management as key, which confirms Risholt and Berker (2013). All groups considered introducing one main contact point as a key value proposition that might appeal to the homeowner, which might suggest the validity of the appeal of this customer value as suggested by various authors (Vanhoutteghem et al. 2011; Haavik et al. 2012a, 2012b, 2012c; Mlecnik et al. 2012; Mahapatra et al. 2013; Mlecnik et al. 2013; Galiotto et al. 2016; Grøn Bjørneboe et al. 2017). However, the results also show that only a few consortia implemented this in practice.

For all consortia, delivering a good homeowner advice was a key customer value to be addressed. Some consortia reflected on the idea to introduce renovation passports (Fabbri et al. 2016), but found the supporting tools not readily available. For example, all consortia emphasised the need to provide an initial analysis or energy audit to secure a solid foundation for the decision-making process. However, in most consortia, it was difficult to identify how the advice would be financed as homeowners are usually not willing to pay for such an energy advice, and how the advice could be given by 'independent' advisers that are trusted by homeowners.
Some consortia also included assistance in financing the renovation as a customer value, typically focusing on lessening the burden on the homeowner in having to apply for grants and subsidies. Other value propositions listed by the consortia are improved aesthetics and functions after renovation, increased value of the house after renovation, tidiness during work, a maintenance-free home for many years, lower operating costs and documentation of the upgrading.

The channels of communication that all the consortia identified were similar with a specific focus on local channels. Often, they defined a long list of channels without insight into their effectiveness. These typically include advertising and information folders, and social media and press coverage, but also the use of demo projects and allowing customers to serve as ambassadors for neighbouring renovations, as well as collaboration with specific networks. Many enterprises appeared to struggle to attract customers through their usual channels.

Some consortia identified specific channels related to the activities of consortium members, for example information events for homeowners, participation in exhibitions at construction fairs or an information booth at a local hardware store. New initiatives include the development of mobile advice centres in neighbourhoods.

A survey conducted amongst homeowners as part of the COHERENO project (Mlecnik and Straub 2015; COHERENO 2016) also showed that customer confidence needs to be improved by providing appropriate quality assurance systems. However, most consortia only suggested to use known brands and references for gaining customer trust. A few consortia made the link with after-sales guarantees, control and service. Some consortia expected to generate customer confidence by making the homeowner an ambassador, showing open book calculations and devising their own communication channels. Many consortia emphasised a research need for a quality system and an internal communication platform for managing overall quality, and the need for tools that visualise the design and those that calculate the financial benefits.

Key activities, key resources and financial logic

Related to the defined customer value 'independent advice', a majority of the consortia included energy audits and advice and design and planning of solutions as a key service. Consortia in countries where public 
bodies offer grants to homeowners for buying an energy audit readily implemented this service in their business model. Most consortia sought to offer a total package and to sign one contract with the homeowner, but not all consortia insisted on doing so. Many consortia had difficulties in understanding the impact of independent advice on their key resources. Some consortia observed that the need for independent advice may conflict with the business idea of being a complete one-stop-shop that includes consultancy. Consequently, a few emerging business collaborations split their consortium into an interdependent informing/consulting group and a contracting/installing group.

The key activities of consortia can differ according to who is leading the business model. This is illustrated for two business models in Table 2 .

The consortia all identified the need for key resources such as an energy advisor/architect and a project manager (either the architect or main contractor), motivated and skilled craftsmen, materials, tools and equipment. Most consortia introduced such professionals in their group during the business modelling, either as a group

Table 2 Differences in key activities for two explored consortia where a contractor or an architect is in the lead

Example of lead actor Key activities for this consortium of a consortium

\begin{tabular}{|c|c|}
\hline Contractor & $\begin{array}{l}\text { - Marketing/finding customers } \\
\text { - Identifying the needs (energy audit) } \\
\text { and advising on measures } \\
\text { - Detailed planning and calculation } \\
\text { (visualise values for the home owner) } \\
\text { - Signing of contract } \\
\text { - Construction/implementation, } \\
\text { including project management and } \\
\text { coordination } \\
\text { - Quality assurance } \\
\text { - Hand-over } \\
\text { - Invoicing and follow-up, including } \\
\text { 1-year service or service contract }\end{array}$ \\
\hline Architect & $\begin{array}{l}\text { - Use of consulting catalogue/matrix } \\
\text { - Identifying needs and design according } \\
\text { to an integrated solution } \\
\text { - Promptly calculating project costs } \\
\text { - Individual composition of team for } \\
\text { each project } \\
\text { - Organise all collaborators in order to } \\
\text { increase common understanding and } \\
\text { motivation } \\
\text { - Quality assurance during the process } \\
\text { and follow-up }\end{array}$ \\
\hline
\end{tabular}

member or as a key partner. Four categories of key partners were specified by a majority of the consortia: (1) partners who provide renovation services (product and material suppliers, subcontractors for missing disciplines), (2) partners who can effectively reach possible clients (networks, local non-profit organisations aimed at sustainability, homeowner associations, hardware stores), (3) local/regional/national authorities for supporting policies as well as providing subsidies (municipalities or provinces, energy agencies, organisations offering subsidies) and (4) financial supporters (banks and public authorities offering specific loans for energy efficiency measures, innovation agencies).

Most consortia pointed to the importance of good agreements and understanding, and a strong contract between all consortium members and key partners. A formal contract was, however, not always drawn up when establishing the consortium. Some consortia actively sought to partner with local communities, municipalities, regional energy agencies or scientific actors particularly for organising information events, door-todoor approaches for finding customers or for establishing regional networks. Some consortia now actively work together with such members or with intermediaries in a wider commercial or public space, such as utility companies (for reaching out to homeowners), banks (for offering financing) or hardware stores (for attracting customers via a shop-in-shop concept). Such partnering arrangements suggest that also public-private partnerships can emerge from collaborative business model development.

Some consortia include a physical shop or contact point or logistics system as a key resource, or specific members such a sales manager or supplier. One-stopshop collaborations emphasised the need for transparency (e.g. open book calculations). In those instances, a single consortium member offered full-service packages, including consulting, independent energy audit, renovation, follow-up independent quality control and commissioning and financing.

Most consortia had difficulties defining their revenue streams. This also indicates a limitation of the use of the business model canvas as an explorative tool for business model development for consortia. It was particularly difficult to achieve revenue agreements between informing and/or consulting consortium members and the contractors and/or installers. Consortia differed very much in how they defined their pricing schemes. For example, some aimed to offer a fixed or conditional 
price or a 'menu' price list, whereas others define customer-based revenue depending on the owner's financial situation. A few consortia wished to offer phased renovation processes and included a possibility of splitting the timing of the financing and the work over more than a year. Some consortia aimed to work with provisions from the participating contractors for partially financing a front office or project management.

It was also observed by all consortia that besides salaries for key personnel and craftsmen, tools, equipment and material costs, additional costs might occur such as those related to marketing and exhibition; information channel development (e.g. a web portal); the development of the integrated concept; rent, financing and insurance; an award fee for the advisor or homeowner who brings in a new customer; or insurance related to warranties and claims (e.g. when predicted energy performances are not achieved). The business models revealed tension between being given independent energy advice and paying for it. The experiences from the consortia offer no clear guidance on this, but usually the initial advice is offered for free and the costs are covered by the projects obtained or by the collaborating consortium members.

Usefulness of the business model as a market device for developing collaboration

Analysing the historical profiles of the participating SMEs and the reports of the initial meetings, we can observe that most companies did not readily have customer-oriented marketing material to position themselves on the market of SFH energy renovations. Only a few companies could deliver information about previous integrated renovation projects. The meeting documents show that for most companies, their experiences were a first introduction to business models and to the importance of target groups and customer values in marketing. One could speculate if this observation represents an overall lack of marketing experience for SMEs in the construction sector. A few companies specifically said 'we usually only do what the homeowner asks us to do'. The merit of the business model for such companies was that it made them reflect on their positioning in the market and on the need for collaboration when addressing integrated renovations.

Using the business model for discussing collaboration highlighted the importance of certain innovation barriers. For example, the idea of providing quality assurance, project management or structured advice to owners of SFHs was new to many consortia. Coordinators also need to be paid, but homeowners find it difficult to realise the added value of project management and quality assurance.

Generally, larger consortia experienced greater difficulty and needed more time to develop a joint business model. Smaller consortia, as well as persons who already knew each other, came to a common understanding more quickly. All consortia noted positive experiences using the business model as a joint working tool, mainly because the brainstorming around the canvas also generated knowledge exchange and trust amongst consortium members. Almost all the studied consortia had internal follow-up meetings and developed their business model further by first introducing showcases and then conducting follow-up renovation projects.

Some companies had difficulty setting up joint projects, or experienced insufficient merging of interests to continue consortium formation after the business model development. In these cases, the companies continued to develop their ideas individually.

As the business model canvas was developed for individual businesses, its use in exploring the business model of consortia was found to be experimental and mainly useful in discussing the customer interface. For future business development approaches, it might therefore be more useful to focus on customer journey models or models identifying homeowner adoption decision processes.

Sometimes, interpretation problems occurred when the owner of the business model was not specified from the beginning. Also, the canvas can be regarded from the perspective of the consortium serving other companies as clients, or alternatively as a model for the individual businesses serving homeowners. It takes time to decide who will be the owner of the business model. If for example the group agrees that one of the companies should be the single contact point to invoice the client, the business model development should be considered from this perspective. In cases where the owner is not obvious, the plan would be to develop a consortium (as one would for a corporate business).

After the business model, there is a need to define a detailed action plan which requires full transparency about possible revenues, costs and legal consequences when collaborating formally or informally. The development of such an action plan is not always guaranteed from business modelling alone. The consortium 
members are aware that a successful example requires priority for scheduling their activities. After developing their joint business model, many of the consortia still experienced difficulties in selling their services to homeowners, but this also pushed them to take further action. In Table 3, an overview is provided on how the consortia perceived and solved additional barriers.

Research limitations and opportunities

The research did not look into business models of consortia outside the scope of the involved countries and the COHERENO project. Conclusions may be different if other business objectives or countries are targeted. Our approach has limitations because it was not possible to investigate the role of individual stakeholders or other parts of the housing market (social rent, apartments, residential neighbourhoods and so on). Also, business model development might have been different if a marketing promise of a large number of homes or collaboration with large companies was included. We also did not specifically look into trust issues between consortium members. Hence, the study may potentially lack some relevant details. However, the current study differs from previous studies by introducing the business model for collaborative development and by focusing on supply-side activation for owner-occupied SFH renovation as a validation case. In addition, our work is more concerned with benefits provided by the use of business models to increase market uptake.
Most of the studied consortia confirmed that the structured guidance provided by the business model facilitators - and thus the action research-led to business development, thus confirming the specified objective of market development by means of action research planning and execution. The guidance is now no longer provided and yet the business collaborations continued in one way or another. Based on the experiences from the COHERENO consortia and their interactions with stakeholder groups, various key issues can be identified for further action research development. These include alliance formation of homeowners, introducing quality assurance related to energy performance (including certified energy audits and, for example, energy-saving monitoring and performance guarantees), developing the customer journey based on client wishes and collaborating with municipalities for alliance formation. All the studied consortia also confirmed the need for a real demonstration project to learn for their marketing-trialability allows to determine whether the needs and values of the customer segment are well addressed-which suggests further research opportunities for innovation development. One can speculate if local authorities and innovation and energy policy agencies can continue support of actionbased research for collaborative business model development using dedicated incentives. Similar approaches could for example be tried for specific target groups, for developing public-private partnerships, for alliancing with larger companies, for
Table 3 Barriers and possible solutions as perceived by consortia which already developed a business model for providing energy renovations of single-family homes (as experienced by 24 COHERENO consortia)

\begin{tabular}{|c|c|}
\hline Encountered barriers & Implemented solutions \\
\hline Reaching out to larger groups of homeowners & $\begin{array}{l}\text { Information events in local communities } \\
\text { and municipalities }\end{array}$ \\
\hline Creating market momentum & Establish local networks/introduce grants \\
\hline $\begin{array}{l}\text { Need for special solutions to convince } \\
\text { homeowners }\end{array}$ & Advanced renovation potential analysis \\
\hline $\begin{array}{l}\text { Insufficient budget to complete the } \\
\text { business model }\end{array}$ & Innovation funding \\
\hline Lack of time to develop consortium & Hire new employees (innovation funding) \\
\hline Conflicting interests of collaborators & Form new consortium structure \\
\hline Focus remains on single measures & $\begin{array}{l}\text { Collaborate with external actors offering } \\
\text { integrated solutions }\end{array}$ \\
\hline Lack of information about homeowners' needs & Poll homeowners in target districts \\
\hline Lack of regional embedding of the offer & $\begin{array}{l}\text { Collaborate with energy agencies and } \\
\text { municipalities }\end{array}$ \\
\hline Lack of technical proof of concept & Develop demonstration and testing \\
\hline Lack of interest from policy makers & Start networks based on policy plans \\
\hline
\end{tabular}


developing geographical approaches and so on, as these can support further market development.

\section{Conclusions}

This research aimed to better understand the usefulness of the business model as a market device for collaborating firms for realising owner-occupied energy renovations, by analysing literature and specific experiences from a European project.

The market for SFH energy renovations is still largely dominated by SMEs with limited competencies. The literature identifies a specific need for networking and collaborative business development. Despite the urgency of SFH energy renovations, suitable business models for single-family homes are still emerging and being tested. One possible way forward is to stimulate innovative stakeholders to work together to offer integrated renovation solutions. However, aspiring consortium members might have difficulties understanding each other's perspectives and thus translating their ideas into a common strategy. Business models can help translate a strategy into a logical framework for value creation (Osterwalder 2004), and related tools can be used to guide emerging consortia in their business model development. Collaborative business model development allows service providers to jointly define incentives for long-term integrated services, enables and empowers the aspiring consortium members to achieve a long-term goal, and initiates views on how to achieve short-term returns and overcome remaining barriers.

In the COHERENO project, the business model canvas was introduced as a method to stimulate collaborative development of consortia, involving existing businesses, especially SMEs that aim to collaborate in offering integrated renovation services to individual households. An action-based research plan successfully led to business development by 24 consortia, thus illustrating the importance of action-based research to speed up market development.

The paper demonstrates that a variety of frontrunner consortia can be stimulated to offer SHF energy renovations when using an open-ended invitation for helping them with their business model development. Business model 'owners' can be contractors, consulting actors (e.g. architects) and even local or regional authorities.
In such consortia, other intermediaries (e.g. banks, hardware stores, energy distribution authorities) can play an important role as key partner. Even public-private partnerships can emerge. Various consortia develop different business models, but there are also many similarities to the use of business models.

Based on the lessons from the emerging business models, the following key issues are identified for collaborative business model development for SFH renovation. It is essential to have a clear idea of the target group and to discuss the need for one contact point and sender of invoices.

The research shows that current SMEs in the SFH energy renovation sector often lack knowledge of the basic tenets of business models and marketing, particularly when it comes to defining the customer interface. They have a poor understanding of customer segments, are largely unaware of important customer values to gain customer confidence, such as quality assurance, and are unaware of the effectiveness of chosen customer channels. Collaborative business model development can result in a better understanding of target groups and value propositions.

Collaborative business model development can also lead to joining key resources, redefining activities and discovering new financial approaches towards the homeowner and to support collaboration. It remains a challenge to determine a fair risk distribution between partners, for example, to be able to integrate independent advice in business models. Companies that intend collaborative business model development have to keep in mind that it takes time to build relationships between partners, and transparency is required to find the right cost structure. Additional barriers may emerge after business model development. An integrated perspective can be discussed using business modelling tools, but in a later stage, also action plans need to be developed, also taking into account a specific joint learning trajectory for trialling the business.

Based on our findings, we can recommend continued support of action research initiatives for collaborative business model development for energy renovations, covering for example specific customer segments, apartments, neighbourhoods, alliancing with local authorities or large companies and so on. The chances are high that such initiatives can lead to speeding up the market development of energy renovations. 
Acknowledgements This paper summarises findings from the project 'COHERENO - Collaboration for housing nZEB renovation' (COHERENO 2016). All COHERENO partners contributed to this research (http://www.cohereno.eu/about/consortiumpartners.html). The COHERENO project was co-funded by the Intelligent Energy Europe Programme of the European Union. The sole responsibility for the content of this paper lies with the authors. It does not necessarily reflect the opinion of the European Union. Neither the EASME nor the European Commission is responsible for any use that may be made of the information contained therein. This paper was initially presented and discussed during the ECEEE Summer Study 2017. The authors would like to thank the participants and organisers for their valuable comments and reviews, as well as the reviewers. The paper supports the project 'Triple-A: stimulating the Adoption of low-carbon technologies by homeowners through increased Awareness and easy Access', funded by the European Interreg2Seas programme and co-financed by the European Fund for Regional Development (ERFD) and by the Provinces of South Holland and West Flanders.

\section{Compliance with ethical standards}

Conflict of interest The authors declare that they have no conflict of interest.

Open Access This article is distributed under the terms of the Creative Commons Attribution 4.0 International License (http:// creativecommons.org/licenses/by/4.0/), which permits unrestricted use, distribution, and reproduction in any medium, provided you give appropriate credit to the original author(s) and the source, provide a link to the Creative Commons license, and indicate if changes were made.

\section{References}

Abuzeinab, A., Arif, M., Quadri, M. A., \& Kulonda, D. (2018). Green business models in the construction sector: an analysis of outcomes and benefits. Construction Innovation, 18(1), $20-42$.

Aho, I. (2013). Value-added business-models: linking professionalism and delivery of sustainability. Building Research \& Information, 41(1), 110-114.

Al-Saleh, Y., \& Mahroum, S. (2015). A critical review of the interplay between policy instruments and business models: greening the built environment a case in point. Journal of Cleaner Production, 109, 260-270.

Artola, I., Rademaekers, K., Williams, R., Yearwood, J. (2016). Boosting building renovation: what potential and value for Europe?, Study for the Policy Department A: Economic and Scientific Policy, European Parliament, European Union.

BetterHome. (2017). The BetterHome renovation service. Retrieved from: http://bpie.eu/wp-content/uploads/2017/10 /INFOGRAPHIC_BETTERHOME_03.pdf, consulted 03 /02/2018.
Boons, F., \& Lüdeke-Freund, F. (2013). Business models for sustainable innovation: state-of-the-art and steps towards a research agenda. Journal of Cleaner Production, 45, 9-19.

BPIE. (2011). Europe's buildings under the microscope. Brussels: Building Performance Institute Europe.

COHERENO (2016). COHERENO - collaboration for housing nZEB renovation, Intelligent Energy Europe project (20122016). All reports available on http://www.cohereno. eu/about/project-outcomes.

Disconzi, F., \& Lorenzoni, A. (2017). ICT tools to foster smalland-medium-enterprise collaboration in the energyretrofitting sector, in: A. Bisello et al. (eds.), Smart and sustainable planning for cities and regions, green energy and technology, DOI https://doi.org/10.1007/978-3-31944899-2_22, 383-405.

Doganova, L., \& Eyquem-Renault, M. (2009). What do business models do? Innovation devices in technology entrepreneurship. Research Policy, 38, 1559-1570.

EC. (2016). Proposal for a Directive of the European Parliament and of the Council amending Directive 2010/31/EU on the energy performance of buildings. Brussels: European Commission.

EU. (2011). Roadmap for moving to a low-carbon economy in 2050. Brussels: European Union.

Eurostat (2011). People in the EU-statistics on housing conditions, available on-line: http://ec.europa.eu/eurostat/statisticsexplained/index.php/People_in_the_EU_\%E2\%80\%93_ statistics_on_housing_conditions, consulted 03/02/2018.

Fabbri, M., De Groote, M., Rapf, O. (2016). Building renovation passports: customised roadmaps towards deep renovation and better homes, 2nd edition, Building Performance Institute Europe.

Galiotto, N., Heiselberg, P., \& Knudstrup, M. (2016). Integrated renovation process: overcoming barriers to sustainable renovation. ASCE Journal of Architectural Engineering. https://doi.org/10.1061/(A S CE)AE.19435568.0000180 .04015007$.

Greenwood, D.J. \& Levin, M., (2007) Introduction to action research: social research for social change. Sage Publications, London, $2^{\text {nd }}$ edition.

Grøn Bjørneboe, M., Svendsen, S., \& Heller, A. (2017). Using a one-stop-shop concept to guide decisions when single-family houses are renovated. ASCE Journal of Architectural Engineering, DOI: https://doi.org/10.1061 /(ASCE)AE.1943-5568.0000238, pp.11.

Güneralp, B., Zhou, Y., Ürge-Vorsatz, D., Gupta, M., Yu, S., Patel, P. L., Fragkias, M., Li, X., \& Seto, K. C. (2017). Global scenarios of urban density and its impacts on building energy use through 2050. Proceedings of the National Academy of Sciences, 114(34), 8945-8950.

Haavik, T., Aabrekk, S., Mlecnik, E., \& Kondratenko, I. (2012a). Opportunities and barriers for business modelling of integrated energy renovation services, In: Andresen I. et al. (Eds.), PassivhusNorden 2012, Trondheim, Akademika Forlag, Tapir Akademisk Forlag, 1-8.

Haavik, T., Aabrekk, S.E., Mlecnik, E., Cré, J., Kondratenko, I., Paiho, S., Grøn, M, Hansen, S., van der Have, J.A., Vrijders, J., \& Mostad, K. (2012b). Guidelines how to develop a business model for one stop shop house renovation. ERA-NET Eracobuild project One Stop Shop "From demonstration 
projects towards volume market innovations for one stop shop in sustainable renovation", http://www.one-stop-shop.org.

Haavik, T., Mlecnik, E., \& Rødsjø, A. (2012c). From demonstration projects to volume market of sustainable construction. Energy Procedia, 30, 1411-1421.

Häkkinen, T., \& Belloni, K. (2011). Barriers and drivers for sustainable building. Building Research \& Information, 39(3), 239-255.

Hilderson, W., Mlecnik, E., \& Cré, J. (2010). Potential of low energy housing retrofit. Insights from building stock analysis, final report from the LEHR project, Federal Science Policy, Belgium, available on-line: http://www.lehr.be, consulted 03 /02/2018.

Holm, M. van, Thuring, M., \& Vandevelde, B. (2016). Report on creating customer confidence through quality assurance. COHERENO International report. Available at: http://www. cohereno.eu, consulted 03/02/2018.

Johnson, M. W., Christensen, C. M., \& Kagermann, H. (2008). Reinventing your business model. Harvard Business Review, 86(12), 57-68.

Killip, G. (2013). Products, practices and processes: exploring the innovation potential for low-carbon housing refurbishment among small and medium-sized enterprises (SMEs) in the UK construction industry. Energy Policy, 62, 522-530.

Killip, G., Fawcett, T., \& Janda, K. B. (2014). Innovation in lowenergy residential renovation: UK and France. Proceedings of the Institution of Civil Engineers - Energy, 167(3), 117-124.

Kivimaa, P., \& Martiskainen, M. (2017). Innovation, low energy buildings and intermediaries in Europe: systematic case study review. Energy Efficiency, 11, 31-51. https://doi.org/10.1007 /s12053-017-9547-y.

KP Renovatie (2017), Kennisplatform renovatie: innovatie in renovatie, ten experimental project funded by the Flemish Enterprise Agency, https://www.kennisplatform-renovatie. be/proeftuinprojecten/ (in Dutch), consulted 03/02/2018.

Mahapatra, K., Gustavsso, L., Haavik, T., Aabrekk, S., Svendsen, S., Vanhoutteghem, L., Paiho, S., \& Ala-Juusela, M. (2013). Business models for full service energy renovation of singlefamily houses in Nordic countries. Applied Energy, 112, $1558-1565$.

Mlecnik, E. (2013). Innovation development for highly energyefficient housing. PhD. Thesis. Delft: Delft University of Technology.

Mlecnik, E. (2014). Which factors determine the success of strategic niche developments?: Reflections from the emergence of a passive house network. Construction Innovation, 14(1), 36-51.

Mlecnik, E. (2016). Activating the adoption of innovation: lessons from a passive house network. Built Environment Project and Asset Management, 6(2), 205-217.

Mlecnik, E., \& Straub, A. (2014). Barriers and opportunities for business collaboration in the nZEB single-family housing renovation market. http://www.cohereno.eu/about/projectoutcomes, consulted 03/02/2018.

Mlecnik, E., \& Straub, A. (2015). Experiences of homeowners regarding nearly zero-energy renovations and consequences for business models, in: Proceedings of the PLEA 2015 conference, Bologna, 9-11 September 2015.

Mlecnik, E., Kondratenko, I., Cré, J., Vrijders, J., Degraeve, P., van der Have, J.-A., Haavik, T., Aabrekk, S. A., Grøn, M., Hansen, S., Svendsen, S., Stenlund, O., \& Paiho, S. (2012).
Collaboration opportunities in advanced housing renovation. Energy Procedia, 30, 1380-1389.

Mlecnik, E., Kondratenko, I., \& Haavik, T. (2013). Opportunities and barriers related to supply chain collaboration for delivering integrated single-family home renovations. In J. V. McCarthy (Ed.), CIB World Building Congress 2013 (pp. 1-12). CIB: Brisbane.

Nejat, P., Jomehzadeh, F., Taheri, M. M., Gohari, M., \& Majid, M. Z. A. (2015). A global review of energy consumption, CO2 emissions and policy in the residential sector (with an overview of the top ten $\mathrm{CO} 2$ emitting countries). Renewable and Sustainable Energy Reviews, 43, 843-862.

OECD (2001). Innovative networks. Co-operation in national innovation systems. Paris: OECD Publishing. ISBN 9789264195660 .

One Stop Shop (2012). From demonstration projects towards volume market: innovations for sustainable renovation. ERANET-ERACOBUILD project. Antwerpen: PHP. Available at: http://www.one-stop-shop.org, consulted 03/02 $/ 2018$.

Ornetzeder, M. \& Rohracher, H. (2009). Passive houses in Austria: the role of intermediary organisations for the successful transformation of a socio-technical system, in the Proceedings of the ECEEE 2009 Summer Study, France, $1531-1540$.

Osterwalder, A. (2004). The business model ontology: a proposition in a design science approach, Academic dissertation, Universite de Lausanne, Ecole des Hautes Etudes Commerciales, 2.

Osterwalder, A., \& Pigneur, Y. (2010). Business model generation: a handbook for visionaries, game changers, and challengers. New York: Wiley.

Osterwalder, A., Pigneur, Y., \& Tucci, C. L. (2005). Clarifying business models: origins, present, and future of the concept. Communications of the AIS, 15, 1-39.

Owen, A., Mitchell, G., \& Gouldson, A. (2014). Unseen influence - the role of low carbon retrofit advisers and installers in the adoption and use of domestic energy technology. Energy Policy, 73, 169-179.

Pitt, M., Tucker, M., Riley, M., \& Longden, J. (2009). Towards sustainable construction: promotion and best practices. Construction Innovation: Information, Process, Management, 9(2), 201-224.

Porter, M. (1998). Clusters and the new economy of competition. Harvard Business Review, 76(6), 77-91.

Reason, P., \& Bradbury, H. (2005). Handbook of action research: participative inquiry and practice (4th ed.). London: Sage Publications.

Refurb (2017), Horizon 2020 project, http://go-refurb.eu/, consulted 03/02/2018.

Risholt, B., \& Berker, T. (2013). Success for energy efficient renovation of dwellings-learning from private homeowners. Energy Policy, 61, 1022-1030.

Rødsjø, A., Prendergast, E., Mlecnik, E., Haavik, T., Parker, P. (2010) From demonstration projects to volume market. Market development for advanced housing renovation, report of the IEA SHC Task 37, retrieved from http://task37.iea-shc. org/Data/Sites/1/publications/Advanced_Housing_ Renovation.pdf, consulted 03/02/2018.

Rogers, E. M. (2003). Diffusion of innovations (5th ed.). New York: Free Press. 
Ruelle, C., \& Teller, J. (2016). Guided group purchases of energy renovation services and works in deprived urban neighbourhoods. Energy Efficiency, 9(4), 861-874.

Saini, M., Arif, M., \& Kulonda, D. J. (2018). Critical factors for transferring and sharing tacit knowledge within lean and agile construction processes. Construction Innovation, 18(1), 64-89.

Sandberg, N. H., Sartori, I., Heidrich, O., Dawson, R., Dascalaki, E., Dimitriou, S., Vimmr, T., Filippidou, F., Stegnar, G., Zavrl, M. S., \& Brattebø, H. (2016). Dynamic building stock modelling: application to 11 European countries to support the energy efficiency and retrofit ambitions of the EU. Energy and Buildings, 132(Suppl. C), 26-38.

Sommer, A. (2012). Managing green business model transformations. Berlin: Springer Verlag.

SuccessFamilies. (2012). Successful sustainable renovation business for single-family houses. Nordic Innovation report 2012:21. Oslo: Nordic Innovation.

Teece, D. J. (2010). Business models, business strategy and innovation. Long Range Planning, 43(2-3), 172-194.

Tofield, B., \& Ingham, M. (2012). Refurbishing Europe: an EU strategy for energy efficiency and climate action led by building refurbishment. Norwich: UK Low Carbon Innovation Centre and Build with CaRe.
Tuominen, P., Klobut, K., Tolman, A., Adjei, A., \& de BestWaldhober, M. (2012). Energy savings potential in buildings and overcoming market barriers in member states of the European Union. Energy and Buildings, 51, 48-55.

Vanhoutteghem, L., Tommerup, H.M., Svendsen, S., Paiho, S., Ala-Juusela, M., Mahapatra, K., Gustavsson, L., Haavik, T., \& Aabrekk, S.E. (2011). Full-service concept for energy efficient renovation of single-family houses, In the Proceedings of the SB11 World Sustainable Building Conference, Finnish Association of Civil Engineers, Helsinki, Finland, 1323-1330.

West, M. A., Hirst, G., Richter, A., \& Shipton, H. (2004). Twelve steps to heaven: successfully managing change through developing innovative teams. European Journal of Work and Organizational Psychology, 13(2), 269-299.

Wilson, C., Pettifor, H., \& Chryssochoidis, G. (2018). Quantitative modelling of why and how homeowners decide to renovate energy efficiently. Applied Energy, 212, 1333-1344.

Zenker, S. (2009). Who's your target? The creative class as a target group for place branding. Journal of Place Management and Development, 2(1), 23-32. 